\title{
Mental Health and Access to Active Labor Market Programs 1
}

I Magne Bråthen²

PhD Candidate, Oslo Metropolitan University, Department of Social Work, Child Welfare and Social Policy, Norway

I Kjetil A. van der Wel

Professor, Oslo Metropolitan University, Department of Social Work, Child Welfare and Social Policy, Norway

\section{Borghild Løyland}

Associate Professor, Oslo Metropolitan University, Department of Nursing and Health promotion, Norway

\begin{abstract}
This paper examines the often-overlooked precondition for successful implementation of active labor market policy, namely equal access to labor market programs. Focusing on a cohort of social assistance recipients, we compare program participation between individuals who were eligible for vocational training and had reported psychological distress, to possible participants with other health or social challenges. The study covers a period of six years. The results indicate that social services prioritize training for those without mental health problems. This is true independently of observed differences between the two groups in terms of demographic and human capital characteristics, work motivation and self-efficacy. Hence, the study concludes that there seems to be a mental health access bias in program participation among disadvantaged groups. Policy makers and future research should address possible organizational barriers to equal program access.
\end{abstract}

\section{KEYWORDS}

Access bias / active labor market programs / mental health / The Norwegian Labour and Welfare Administration (NAV) / social assistance benefits

\section{Introduction}

mployment rates among people with mental illness in Western countries are commonly observed below $50 \%$, considerably lower than those for the healthy population (OECD 2015, p. 32). The employment gap between people with and without mental illness is around 30 percentage points in Nordic and Liberal welfare states, and somewhat smaller in Conservative welfare states. These sizeable mental health

\footnotetext{
${ }^{1}$ You can find this text and its DOI at https://tidsskrift.dk/njwls/index.

${ }^{2}$ Corresponding author: magbra@oslomet.no.
} 
employment gaps are at odds with supranational and national policy aims of providing and facilitating work among disabled people (UN CRPD 2006, Articles 26-27). They also represent a public health issue, as research suggests that work improves health and reduces psychological distress (Modini et al. 2016). Furthermore, since there is a general need to increase the tax base, research that sheds light on the labor market disadvantage experienced by people with poor mental health is in demand.

In the context of supporting employment for disabled people, the use of active labor market programs (ALMPs) has been strongly advocated by the OECD (2010) and has become an important pillar of the social investment strategy in Europe (Van Kersbergen \& Hemerijck 2012). ALMPs aim at increasing the employability of participants by providing qualifications and skills (supply-side policies) and overcoming the reluctance of employers to hire applicants with disabilities (demand-side policies) (OECD 2013). Much research has been done on the employment-effects of such programs and how they vary across subgroups among the disabled (see Card et al. 2015; Bredgaard 2015). However, less is known about inequalities in access to ALMPs. Institutional logics, available resources as well as conscious and unconscious actions of caseworkers may affect the extent to which people with mental illness are provided the same opportunities within the welfare services as everyone else, what we refer to as the 'access bias'. That ALMPs are indeed delivered to the intended groups, and not to groups that would be better off on their own, is crucial for their efficiency as social policy tools, and pivotal to closing the disability employment gap.

Interestingly, a recent review by Bonoli and Liechti (2018) covering 14 countries documents pronounced biases in access to certain ALMPs to the disadvantage of low-skilled workers and migrants. The study also shows that these access biases vary across social policy contexts. Social Democratic welfare states had negligible access biases, while they were larger in Conservative and Liberal welfare states. However, the review, and no other study we are aware of, have investigated whether the access to ALMPs has a mental health bias. Identifying whether there is a mental health access bias in ALMP participation is potentially important in understanding the mental health employment gap.

Thus, the purpose of this article is to examine whether there is an access bias in the recruitment to ALMPs that favors possible participants without mental health problems in Norway. Given the results in Bonoli and Liechti (2018) concerning policy context, we also investigate whether the resources available to caseworkers influence the size of the possible access bias, by exploiting variation introduced by a welfare reform. We expect that the mental health access bias is susceptible to resource scarcity, that is, that the bias is larger when resources are scarce. Our data do not allow causal modelling and interpretation. However, by controlling our analysis for a wide array of relevant individual characteristics seldom available in such studies, we assess and discuss the influence of a significant change in the caseworkers' decision structure introduced by a well-funded activation program in 2008-2009. We study a traditionally hard-to-serve group, namely long-term social assistance recipients. Since recent welfare reforms have been targeting exactly welfare recipients with complex needs, this group constitutes an interesting case. The social assistance recipients were surveyed in 2005. Using additional information collected from Norwegian administrative registers covering the years from 2004 until 2009, we could follow ALMP participation, employment and the use of public benefits through the reform period.

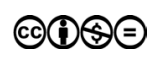




\section{Theoretical background}

ALMPs are principally gated welfare services. According to Bonoli and Liechti (2018), applying a simplified version of Heckman and Smiths' (2004) five-stage model, access to ALMPs is the result of a process consisting of two stages: eligibility assessment and inclusion. Eligibility rules are typically formulated in legal frameworks and guiding directives. Caseworker's eligibility assessments include an evaluation of whether the formal conditions for access to specific measures are fulfilled. However, bureaucratic discretion in interpreting and adapting the eligibility rules also affects recruitment to programs (see Parsons 1991). This happens in the inclusion stage when caseworkers evaluate additional, often more informal features they deem relevant, like social skills and motivation. Access biases are social cleavages in the use of ALMPs that arise from either of these two stages; eligibility rules or welfare agent's priorities and discretionary practices. This definition departs from a purely technical use of the term that also includes biases that stem from clients' preferences and agency. Depending on the rules and practices governing access to ALMPs, access biases may in principle be positive or negative.

Eligibility criteria in ALMPs typically favor disadvantaged groups, since most programs target individuals with low formal skills, long-term unemployed, or persons with health problems. Eligibility criteria may differ between programs and may also change within programs over time. Hence, the overall eligibility structure of all available programs is likely to vary across contexts (Bonoli \& Liechti 2018, pp. 907-908) as well as over time within countries (Duell \& Tergeist 2009; Rønsen \& Skarðhamar 2007), and so will access biases.

Even if access biases work in favor of the disadvantaged in the eligibility stage, these may be offset by 'Matthew effects' in the inclusion stage. Those who end up being offered program participation are those who are the least disadvantaged (Bonoli \& Liechti 2018, p. 898; Heckman \& Smith 2004, p. 245). Caseworkers' decisions about program participation may be influenced by at least two factors (Bonoli \& Liechti 2018). First, client participation in ALMPs require some basic cognitive and non-cognitive skills, like speaking the language, operating and planning skills, and general communication skills. Second, caseworkers may anticipate participants' employability or 'market value' in order to spend scarce resources on those they believe will have a real chance of getting a job. Choosing the ones with the best initial job prospects for program participation is often referred to as 'creaming' or 'cream-skimming' (Bassi 1984; Heckman et al. 2002).

A third factor, however, may be biases arising from administrative incentives. New Public Management principles introduced in welfare services commonly link budgets to successful transition of cases into work. This may have incentivized caseworkers or ALMP providers to prioritize the least disadvantaged in labor market programs (Rodriguez-Planas 2010).

Fourth, the professional background of caseworkers and changes over time in the composition of caseworkers may play a role. Trained social workers typically have internalized professional values that favor disadvantaged participants and may have a more pragmatic and discretionary application of recruitment rules. However, many caseworkers have other educational backgrounds, which may make them more inclined to follow rules more strictly (Caswell \& Larsen 2017). Finally, specific disadvantages like drug abuse, mental illness or ethnicity may be associated with discrimination and stigma, also within welfare services (OECD 2012; Sutton 2004; Willams \& Johnson 2010). 


\section{Institutional context}

Mental illness is one of the most common reasons for disability pension in Norway, and the employment rate among people with mental disorders in Norway is about half compared to other disabled people, even though people with mental illness are more often motivated for work (Statistics Norway 2017). The same pattern can be found across the OECD (OECD 2015). To reverse the trend of an increasing number of people who drew welfare benefits instead of participating in the workforce, a new public agency was established in 2006, the Norwegian Labour and Welfare Administration (NAV) (Lægreid \& Rykkja 2013). In the wake of this reform, the Government introduced several changes to the activation strategies targeted at disadvantaged groups outside the labor force (Duell $\&$ Tergeist 2009). The most important program targeting long time recipients of social assistance benefit was the Qualification Program, which was announced in 2007 as a key initiative related to poverty reduction in Norway. We will describe these reforms in more detail below.

In Norway, social assistance is the final safety net granted only if the individual in question has exhausted all other potential income sources. It is an explicit aim that this benefit is to be a temporary economic support, while the individual (and his/her family) becomes self-sufficient. In order to enhance recipient's employability, social workers may provide offers of participating in ALMPs that give work-related training and practice. Which groups that are recruited may vary over time, across municipalities and types of programs (Dahl \& Lorentzen 2007). Mental health has rarely been scrutinized as a selection factor to ALMPs (Dahl 2003; Hardoy 2005; Zhang 2003).

\section{The NAV reform}

The establishment of NAV in 2006 is considered one of the largest public administration restructurings in Norwegian history. By merging the previously separate labor and welfare administrations and through establishing local one-stop shops (NAV-offices) in every municipality in Norway, the Government hoped to deliver more integrated and effective services. The reform particularly aimed at improving services for claimants with multiple needs and complex problems (Askim et al. 2011). This included making ALMPs more accessible to a wider group of users. However, initial evaluations showed that the reform came with short-term costs for users of the services NAV provide. The implementation process itself demanded resources from the caseworkers at the expense of work-related follow-up particularly during the first years of the reform period (Schafft $\&$ Spjelkavik 2011). In addition, there was also a perception that the role of the social worker changed in the new organization. Employees expressed that the NAV reform left less room for what they regarded as the professional knowledge and autonomy of social workers (Røysum 2010).

\section{The introduction of the Qualification Program}

Late 2007, the Government launched the Qualification Program where the main goal was to increase employment among claimants with severely reduced earnings capacity 
and with no or very limited social insurance entitlements. The program recruited persons who had become or were at risk of becoming reliant on social assistance benefits (Markussen \& Røed 2016). The idea of the program was to commit participants to full-time activities in individually tailored activation programs, using 'welfare contracts' and strong economic incentives to participate. 'Activation' in the context of the program could not only mean participating in ALMPs but also consultations, medical rehabilitation or therapy, and social training. Recruitment to the Qualification Program includes participants with a variety of challenges and barriers to work. Poor language skills, disrupted schooling, little or no work experience, criminal records, and sometimes mental disorders and drug problems make the program participants hard to employ.

In 2008, the first year of operation, the authorities set a high goal for the expected number of participants. They also provided earmarked grants to the municipalities, meant to cover their additional costs related to the follow-up associated with the program. This gave a huge incentive for the municipalities to recruit long-term social assistance recipients to the program, which the municipalities did (Langeng \& Dehli 2011). The ambitious attendance goal in combination with generous funding introduced a 'shock' to the otherwise scarce resource situation of caseworkers, who could now open the doors to ALMPs for a much larger pool of clients. Notably, an evaluation report including qualitative interviews with caseworkers (Schafft \& Spjelkavik 2011) indicated that hard-to-serve individuals with psychiatric problems and drug abuse still appeared to be avoided. The recruitment, even to this targeted program, seemed to be selective in favor of the better fit. However, it remains to be seen whether the bias increased or decreased.

\section{Analytical approach and research questions}

Our first research question is whether there exists a mental health access bias in ALMP program participation among long-term social assistance recipients in Norway, 2004-2009. The recipients were distant from the labor market; many had health problems, low scores on social capital, a history of substance abuse and had experienced troubles during childhood (van der Wel et al. 2006). By controlling for a wide range of factors not often available to researchers, such as psychological resources and work motivation, we argue that our access bias estimate is independent of case workers' assessments of client characteristics in the inclusion stage of the recruitment process. The observed access bias thus reflects caseworkers' discretionary or informal judgments and priorities in a given resource and eligibility setting.

Our second research question is whether the access bias is susceptible to changes in the resource situation of the caseworkers. In order to answer this question, we divide the follow-up period into three stages. The first period (2004-2005) represents the prereform situation, when access to ALMPs for social assistance recipients was limited. The second period (2006-2007) represents the introduction of the NAV reform, while the latter period (2008-2009) denotes the access situation introduced by the Qualification Program. Both the NAV reform and the new Qualification Program were meant to help vulnerable groups into the labor market through providing new priorities and guidelines for follow-up and making ALMPs more available to clients with complex needs. The implementation processes did however also demand resources that might have affected how the work-related follow-up was performed. 
Hence, the second stage of follow-up expanded the eligibility to ALMPs, but resources were still scarce, meaning that case workers needed to make decisions on who to include, and who to exclude. We hypothesize that these priorities did not work to the advantage of the mentally ill, due to 'cream skimming' mechanisms. In the final stage of follow-up, however, the introduction of the Qualification Program, although temporarily, dramatically changed the resource situation. Given that caseworkers now did not need to consider ALMPs as a scarce resource, we hypothesize that the mental health access bias improved in the final stage.

\section{Data}

\section{The study population}

The study uses data on a cohort of long-term (more than six months) recipients of social assistance benefits, identified and surveyed in 2005. Additional sample criteria were that social assistance benefits constituted the individual's main source of income, and that the recipients were between 18 and 60 years of age. All cohort members were living in one of 14 Norwegian municipalities that took part in a so-called activation trial, a national project where the municipalities received national funding to promote new ways to move long-term social assistance recipients from benefit dependency into work. One of the project's main tools was to improve access to and increase the use of the national active labor market programs, which the recipients of social assistance benefit to some extent had been excluded from due to institutional barriers (Lødemel \& Johannessen 2005).

The population consisted of 1066 recipients, of whom about $50 \%$ returned the questionnaire that provided information on sociodemographic characteristics, work, health, pain, health-related quality of life, use of alcohol and narcotics, and more. This dataset was linked with information from several national administrative registers by Statistics Norway, which enables us to follow vital aspects of their life course over a period stretching from 2004 until 2009. These register data included information on income, use of social assistance, educational level, and participation in activation and labor market programs. In the analyses presented below, those who did not consent to participate in the follow-up study were excluded, which left us with a sample of 446 individuals. The Norwegian Data Protection Authority has given a confidentiality permit allowing the use of the information.

\section{Variables}

Below, we give a detailed description of the variables included in the analysis that might decide the possible participant's access to ALMPs.

\section{Participation in Active Labor Market Programs}

NAV administers most of the programs that provide vocational training. By definition, ALMPs include a wide range of work-related programs for anyone that is unemployed, 
be it due to lack of job availability or health issues. In other words, the programs are targeted both at jobseekers that do not face any particular health problems, and those with a reduced working capacity due to health issues or social problems.

We group the main labor market programs in Norway according to Eurostat's categorization of active labor market policies targeted at unemployed, persons employed but at risk of involuntary job loss and inactive persons who would like to enter the labor market (Eurostat 2013). In the analysis, an individual was classified as a participant if he or she had been registered taking part in one or more of the following programs:

(1) Training

Measures financed by the public body that aim to improve the employability through training, like 'Labor Market Training' and 'Education in regular schools'.

(2) Employment Incentives

Measures that facilitate the recruitment of unemployed persons and other target groups, or that help ensure the continued employment of persons at risk of involuntary job loss, like 'Wage subsidies to employers' and 'Work experience in ordinary enterprises'.

(3) Supported employment and rehabilitation

Measures that aim to promote labor market integration of persons with reduced working capacity through sheltered or supported employment or through rehabilitation, like 'Work experience in sheltered enterprises', 'Supported employment', 'Rehabilitation assessment in sheltered workshops', and 'Work-oriented rehabilitation'.

(4) Direct job creation

Measures that create new jobs, usually with a public utility profile, in order to provide employment for the long-term unemployed or persons otherwise difficult to place like 'Temporary employment measures' for the occupationally disabled.

(5) Start-up incentives

Measures that promote entrepreneurship by encouraging the unemployed and other target groups to start their own business or to become self-employed, like 'Start your own business'.

\section{Employment and Disability Benefit Receipts}

By using information about annual income from work collected by the Norwegian Tax Authorities, we identify if the respondents were gainfully employed or became disability benefit recipients during follow-up. For someone to be classified as employed, we decide that earnings from work had to be the main source of income and that the level of earnings had to be above a certain threshold. To obtain a threshold reflecting real income values over time, we used the so-called basic amount. The basic amount is used as a reference point in calculating pensions and benefits in Norway and is regulated each year by Parliament to reflect the average growth in wages. We choose an income threshold of 1.5 times the basic amount, which is roughly equal to $50 \%$ of the poverty line in Norway.

Similarly, we extract data on disability benefit receipt from the tax register. A person between 18 and 67 insured under the National Insurance Scheme, whose income 
capacity is permanently reduced by at least $50 \%$ due to illness, injury or defect is entitled to the disability benefit. The benefit is granted on a permanent basis until pensioning age.

\section{Psychological distress}

Psychological distress in the form of anxiety and depression, was evaluated using the 10-item Hopkins Symptoms Check List (HSCL-10). Each item is rated on a four-point Likert scale. The total score was calculated as the mean of the 10 individual items.

The cut-off point chosen for the HSCL-10 was 1.85 . Scores above 1.85 indicate that it is highly likely that a psychiatric disorder is present as assessed independently by a clinical interview (see Strand et al. 2003 for discussion of cut-off point). In the study population, $57 \%$ reported psychological distress, that is, had a score above 1.85 . The reliability index, Cronbach's alpha, was 0.92 in our sample.

\section{Work Involvement Scale (WIS)}

As a proxy for the respondent's work ethic, we use the Work Involvement Scale (WIS) (Murray 1984; Warr et al. 1979). WIS measures the non-pecuniary motivation to work, which means the value that respondents attach to work irrespective of income need or job-specific qualities (Nordenmark 1999). It is reasonable to expect that a high WIS scores also indicate a desire to participate in active labor market programs in order to work for reasons other than purely economic ones. The index has been found to be remarkably stable over time. Hyggen (2008) demonstrates that $80 \%$ of 2000 individuals representative of the Norwegian cohorts born between 1965 and 1968 had unchanged WIS scores over a period of 10 years.

WIS has six items graded from complete disagreement to full agreement. The individual sum of the responses is averaged over all items. Higher scores mean higher work motivation. High reliability scores, well above 0.80 , are found in several samples (Halvorsen 1999; Hyggen 2008) and was confirmed in our material as Cronbach's alpha is 0.85 .

\section{Mastery and Self-esteem}

To capture the role of psychological coping resources, we also included information about individuals' general perception of themselves. According to Cast and Burke (2002), this perception consists of two factors: mastery and self-esteem. Both are regarded as important psychological and emotional resources that enable us to act and participate socially, and also make important life choices. The Pearlin Mastery Scale (PM) defines an individual's level of mastery, which is 'the extent to which one regards one's life-chances as being under one's own control in contrast to being fatalistically ruled' (Pearlin \& Schooler 1978, p. 5). This index includes seven items, is additive and varies theoretically between one and five. Higher values indicate higher levels of mastery.

The questionnaire used a five-item short-form version of the Rosenberg Self-Esteem scale to measure global self-worth. The items map both positive and negative feelings 
about the self and were answered using a four-point Likert scale format. The Cronbach's alpha for the two scales were 0.71 and 0.80 , respectively.

\section{Age, Gender, Ethnic Minority and Work Experience}

In addition, the data included information about age and gender. The informants also reported whether they feel part of an ethnic minority. The variable Work Experience captured whether informants had been employed for a period of six months or more. The composition of the group that reported psychological distress differed from the rest of the population, including a higher percentage of women $(47 \%)$, a lower percentage who classified themselves as an ethnic minority $(15 \%)$ and a lower educational level (45\% with high education).

Table I Descriptive statistics, time-invariant covariates.

\begin{tabular}{lcccc}
\hline & Share & Average & Std dev. & Cronbach's alpha \\
\hline Psychological distress & 0.60 & - & - & - \\
\hline Female & 0.41 & - & - & - \\
\hline High education & 0.48 & - & - & - \\
\hline Ethnic minority & 0.19 & - & - & - \\
\hline Work experience & 0.69 & & & \\
\hline Age (I8-59) & - & 33.8 & 10.7 & - \\
\hline Work Involvement Score (I-5) & - & 3.8 & 1.3 & 0.90 \\
\hline Pearlin Mastery Scale (I-5) & - & 3.1 & 0.9 & 0.71 \\
\hline Self-esteem (I-4) & - & 2.5 & 0.7 & 0.80 \\
\hline
\end{tabular}

$N=446$.

\section{Statistical analysis}

The statistical analysis consisted of two parts. First, we present the cohort's overall participation in the ALMPs over the six-year period. The analysis also shows to what extent those who reported psychological distress transitioned into the labor market or qualified for permanent disability benefit compared to others, and as a result, how the need for vocational training developed for the two groups.

Second, to study whether there was a possible access bias in the recruitment to ALMPs, we estimated participation probabilities for individuals who had received social assistance benefits or qualification benefits, and thereby had been in contact with a social worker. The data were split into three two-year periods as described above. For each of the three periods, we identified those in demand of ALMPs. The data was then pooled giving the observational unit; individual $i$ in need of an ALMP in period $t$. To identify the determinants of program participation, the following two linear regression models were used (see Hellevik 2009 for discussion of linear versus logistic regression when the dependent variable is a dichotomy). To correct for possible correlation over 
time of the same units, the standard errors of the coefficient estimates were adjusted for dependence in the residuals.

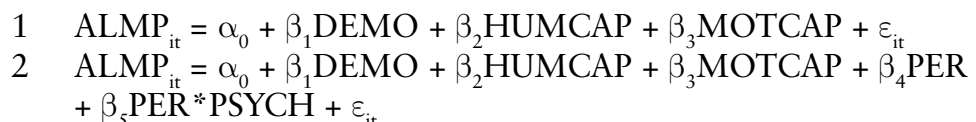

where ALMP, the dependent variable, takes a value of one if the person has participated in one or more of the ALMPs in period $t$, and zero otherwise; DEMO covers demographic characteristics age, gender and immigrant status; HUMCAP is human capital characteristics in the form of educational level and work experience; MOTCAP is work motivation estimated by a work involvement score, and self-efficacy measured by a master and self-esteem scale. In regression model 2, we include dummy variables that represent the five periods (PER) and interaction terms between each period and having reported psychological distress (PER*PSYCH) as predictors for program participation.

\section{Results}

\section{Program Participation and Labor Market Status}

In the six-year period from 2004 to 2009 , about $68 \%$ of the cohort participated in one or more labor market program, which included training measures, Employment Incentives, Supported Employment and Rehabilitation, and Direct Job Creation. That meant that two out of three in the cohort of long-term social assistant benefits had received a follow-up by the support services that included vocational training and practice. The participation rate for individuals who experienced psychological distress was a bit lower than the average, $66 \%$. Consequently, the participation rate among the rest of the cohort was a higher, about $70 \%$.

The difference in program participation between the two groups was however particularly apparent for the programs that provided practice or experience in an ordinary workplace through employment incentives. While $36 \%$ of those categorized with no psychological distress were registered as participants in one or more of these programs, this was true only for about $26 \%$ of those who reported psychological distress.

Table 2 Participation rate in Active Labor Market Programs 2004-2009, by type of program and reported psychological distress.

\begin{tabular}{lccc}
\hline & Total & $\begin{array}{c}\text { Psychological } \\
\text { distress }\end{array}$ & $\begin{array}{c}\text { No psychological } \\
\text { distress }\end{array}$ \\
\hline ALMP participation (2-5) & 68 & 66 & 70 \\
\hline 2. Training & 34 & 33 & 34 \\
\hline 3. Supported employment & 41 & 43 & 38 \\
\hline 4. Employment incentives & 30 & 26 & 36 \\
\hline 5. Direct job creation & 2 & 2 & 3 \\
\hline
\end{tabular}

$\mathrm{N}=$ 446. Per cent. 
Figure 1 shows how the participation rates developed over time for the two groups. The largest observed differences in ALMP activity were registered in 2004 and 2005. In the first year of the observational period, $29 \%$ of the group with psychological distress was participating in a labor market program, compared to $38 \%$ among those with no psychological distress, a 9 percentage point difference. In 2005, the difference between the two groups had increased to 14 percentage points.

The following two years were influenced by the large bureaucratic reform that the establishing of a new labor and welfare service represented. In this period, the ALMP activity dropped for both groups. With the introduction of the Qualification Program in 2008, and the subsequent focus on activating long term recipients of social assistance benefits, the ALMP participation rate rose. The increased program activity was especially imminent for those who had reported physiological distress, with an increase in the participation rate of 12 percentage points.

Figure I Annual Participation Rates in Active Labor Market Programs. 2004-2009. N = 446.

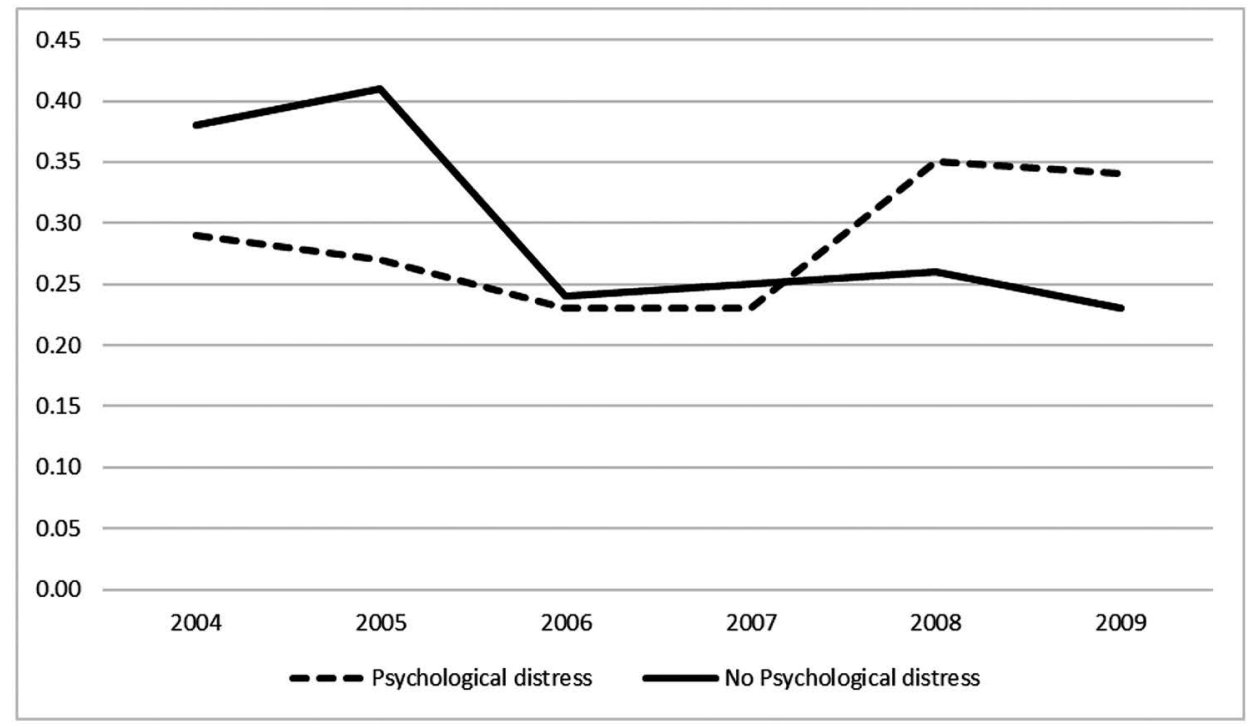

The observed participation rates would be affected by the change in demand of work-related training over time. Some individuals got employment, while others qualified for disability benefits, which meant that their income capacity had been evaluated as permanently reduced. Either of these two statuses might have rendered them outside the target group for the ALMPs. In order to illustrate how the demand for programs changed during the period, Figure 2 shows the employment and disability rates for each year.

The demand for training through labor market programs developed differently for those with and without psychological distress. The share that either got a job or received a permanent disability benefit increased in both groups. In 2004, the employment rate was $8 \%$ for those with psychological distress and just below $10 \%$ for the rest of the 
Figure 2 Annual employment and disability rates. 2004-2009. N = 446.

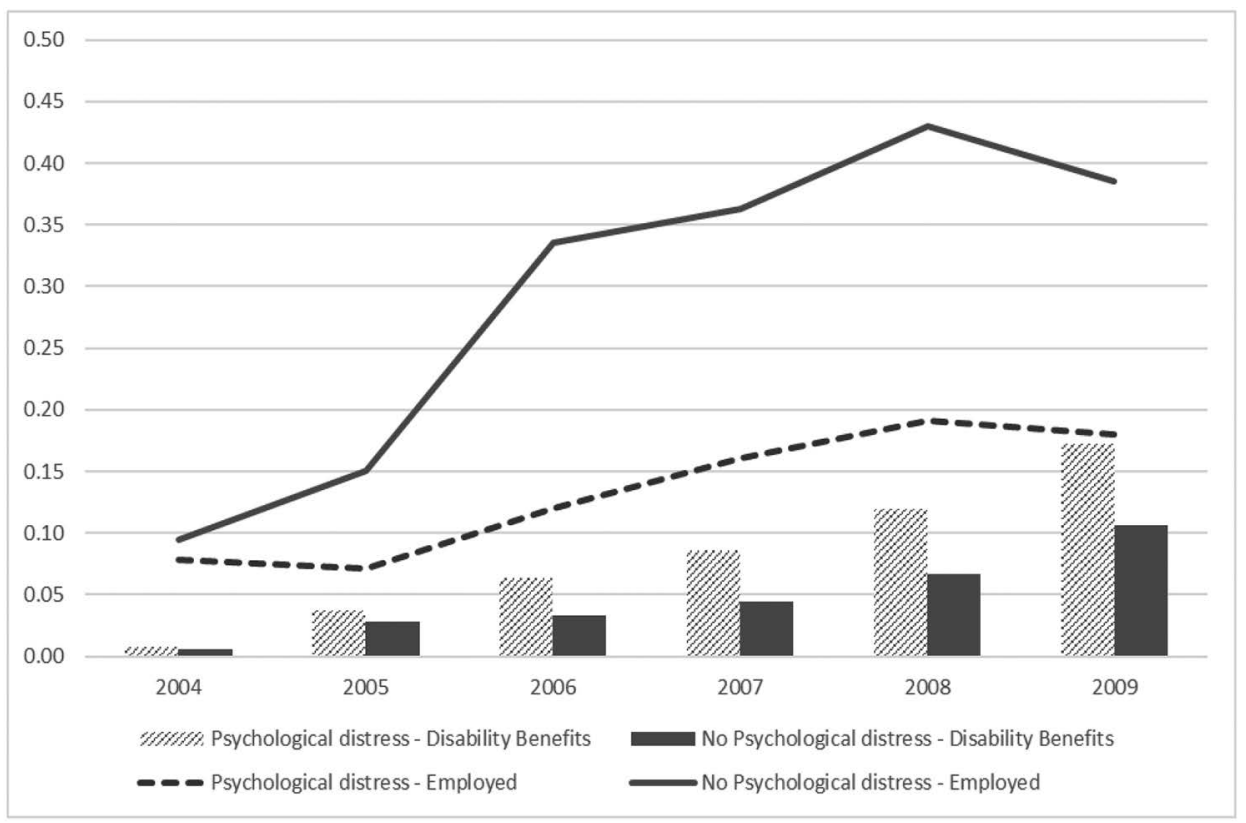

cohort. Two years later, in 2006, the rate had increased to $12 \%$ and $34 \%$, respectively. That is to say, the probability of being employed was about three times as high for those without mental health problems compared to those who experienced psychological distress. This employment gap between the two groups remained the same until the end of the period. The increase in disability rates showed the opposite pattern. A small share of the sample received disability benefits in 2004 . However, the rate increased steadily, but at a higher rate for those who reported psychological distress. In 2009, 17\% of those with psychological distress received a permanent disability benefit compared to $11 \%$ of the rest of the cohort.

\section{The predictors of access to ALMPs}

The descriptive analyses showed that the share of long-term recipients of social assistance benefits who reported physiological distress rates that participates in ALMPs were lower compared to those who did not have the same challenges in the first two, and the last four years of the observation period. Also, the demand for vocational training developed differently over time. What we now want to examine is whether there are indications that the observed patterns can be traced back to the assessments of possible participants made by the case workers. This is done by controlling for the composition of the two groups when it comes to individual characteristics that are assumed to influence program access. 
Table 3 Mental health and ALMP participation. Results from OLS regression analysis.

\begin{tabular}{|c|c|c|c|c|c|c|}
\hline & \multicolumn{6}{|c|}{ Maximum likelihood estimates } \\
\hline & \multicolumn{3}{|c|}{ Model I } & \multicolumn{3}{|c|}{ Model 2} \\
\hline & Estimate & $\begin{array}{l}\text { Robust } \\
\text { SE }\end{array}$ & $\rho$-value & Estimate & $\begin{array}{l}\text { Robust } \\
\text { SE }\end{array}$ & $\rho$-value \\
\hline $\begin{array}{l}\text { Psychological distress } \\
\text { (ref no psychological distress) }\end{array}$ & $-0.100 * *$ & 0.049 & 0.042 & $-0.149 * *$ & 0.060 & 0.013 \\
\hline Female (ref. male) & 0.008 & 0.038 & 0.841 & 0.007 & 0.038 & 0.859 \\
\hline Age I8-29 (ref. 30-49) & 0.009 & 0.041 & 0.834 & 0.010 & 0.041 & 0.813 \\
\hline Age 50-62 (ref. 30-49) & $-0.118 *$ & 0.072 & 0.100 & -0.116 & 0.072 & 0.110 \\
\hline Immigrant (ref. non-immigarnt) & -0.004 & 0.060 & 0.945 & -0.006 & 0.061 & 0.926 \\
\hline High education (ref. low education) & 0.047 & 0.038 & 0.223 & 0.050 & 0.039 & 0.194 \\
\hline $\begin{array}{l}\text { Work experience } \\
\text { (ref. no work experience) }\end{array}$ & 0.001 & 0.043 & 0.820 & 0.011 & 0.043 & 0.800 \\
\hline Work Involvement Score & $0.050 * * * *$ & 0.014 & 0.000 & 0.050***** & 0.014 & 0.000 \\
\hline Pearlin Mastery Scale & -0.001 & 0.029 & 0.979 & -0.001 & 0.029 & 0.982 \\
\hline Self-esteem & -0.025 & 0.035 & 0.478 & -0.136 & 0.035 & 0.453 \\
\hline Period 2, 2006-2007 & . & . & . & $-0.136 * *$ & 0.059 & 0.022 \\
\hline Period 3, 2008-2009 & . & . & . & -0.023 & 0.067 & 0.727 \\
\hline $\begin{array}{l}\text { Psychological Distress*Period 2, } \\
\text { 2006-2007 }\end{array}$ & . & . & . & 0.047 & 0.072 & 0.514 \\
\hline $\begin{array}{l}\text { Psychological Distress*Period 3, } \\
\text { 2008-2009 }\end{array}$ & . & . & . & $0.142 *$ & 0.081 & 0.082 \\
\hline Constant & $0.519 * * * *$ & 0.061 & 0.000 & $0.563^{*} * * * *$ & 0.067 & 0.000 \\
\hline
\end{tabular}

$N=954$ time observations of 446 individuals.

${ }^{* * *}=\rho$-value $<0.01,{ }^{* *}=\rho$-value $<0.05,{ }^{*}=\rho$-value $<0.1$.

The estimated coefficients for Model 1 and 2 presented in Table 3 suggest three important predictors of access to vocational training. First, looking at the whole six-year period, the estimates from the regressions show that there was a significant difference in the ALMP participation rate between those who report psychological distress and the rest of the cohort. The average difference in participation probability was calculated to be about $10 \%$, controlling for covariates. Given that the model captured the most important factors influencing recruitment to the programs, it seemed that within our cohort of social assistance recipients, clients with mental health problems did indeed experience an access bias that favored those without mental health problems.

Second, work motivation significantly changed the possible participants' probability of getting access to vocational training. The higher the work motivation, the higher the probability of being registered in an active labor market program. Apart from age, neither of the variables that described human resources in the form of educational attainment, work experience, human capital or self-efficacy influenced the participation probability.

Third, the implementation of the NAV reform and the introduction of the Qualification Program seem to have influenced program participation. The regression analysis 
shows that the probability of participating in an ALMP was lower $(-0.136$ and $\rho=$ 0.022 ) in the two-year period 2006-2007, irrespective of mental health status in 2005. The interaction term between psychological distress and Period 2 was small and nonsignificant. Hence, the mental health access bias remained unchanged.

Interestingly however, the Qualification Program that especially targeted long-term recipients of social assistance benefits seemed to eliminate the difference in access to vocational training between those with and without mental health problems. The interaction term between the period 2008-2009 and reporting psychological distress $(0.142$ and $\rho=0.082$ ) outweighed the initial mental health access bias.

\section{Discussion}

The analysis presented in this article followed a cohort of long-term recipients of social benefits over six years. In the beginning of the period, most of the recipients were outside the labor market. Several barriers may have prevented them from being in work. Many had health problems, a low educational level and some struggled with substance abuse (van der Wel et al. 2006). Our analysis showed that those reporting psychological distress received ALMPs less often than those who did not, even after we control for other characteristics that might influence the recruitment process.

This mental health access bias in ALMP participation is even more striking if we take into consideration the political backdrop. During the period covered by our analysis, extensive political efforts were made in Norway to create an inclusive work life. This included an emphasis on the importance of individuals with mental disabilities having work, and the need for Nav to supply work-related activities for those outside the labor market (Norwegian Government 2007). Active labor market policies have been based on the underlying assumption that work can improve health through being a source of social relationships, identity, personal growth and financial security, an assumption backed by research on the social determinants of health (Bryant et al. 2010). One would then expect that public efforts made for a more inclusive working life, such as training and practice provided by active labor market programs, were at least equally distributed between those with and without mental health problems.

However, good intentions are not enough. Sufficient funds have to be made available in order to secure equal access to training and practice through ALMPs. This is indicated by the estimated participation probabilities in the period of the introduction of the Qualification Program. Targeted grants to the municipalities to cover additional costs related to follow-up of the recipients of social assistance benefits and providing resources in the form of ALMPs seem to have removed the access bias.

As for explanations, the observed differences in program participation between the two groups can, in line with the access bias hypothesis, be the result of so-called creaming. The caseworkers might have favored job seekers that they regarded as relatively close to the labor market, which they could place in employment with the least effort and investment. This can be the result of what Lipsky (1980) referred to as 'coping mechanisms'. In line with the theories introduced about 'street-level bureaucracy', the employees at NAV would typically experience cross-pressures between limited resources to provide necessary follow-up and the clients demand for services (Røysum 2014). Although the caseworkers have harbored strong ambitions to do good work, 
they might have felt forced to focus their efforts on a limited number of recipients in order to cope with heavy caseloads (Nielsen 2006; Winter \& Nielsen 2008). A rationing of services that prioritizes the presumed easiest clients may be especially imminent if the caseworkers need to deliver a good re-employment rate of participants (Rodriguez-Planas 2010). In Norway, such 'management-by-objectives' (Drucker 1954) is regarded as the dominant management model in government activities, including the public employment service field. Although management-by-objectives systems used by NAV have changed over time, labor market impact indicators regarding 'integration' into employment have remained (Roaldsnes 2018). Since these indicators have not been used to target certain disadvantaged groups, the indicators may have incentivized caseworkers to prefer nonemployed that already had good chances of becoming employment.

One might argue that these findings oppose the results presented by Bonoli and Liechtis' (2018). They conclude that in social democratic welfare states such as Norway, the recruitment to training programs tend to favor the more disadvantaged groups. There are, however, plausible explanations for why the results differ. First, the subpopulations included in the two Norwegian evaluation studies referred to by Bonoli and Liechti (Zhang 2003; Hardoy 2005), were different compared to our cohort. The participants of job seekers that constituted the two analytical populations in their study might be regarded as closer to the labor market and less vulnerable than the long-term social assistance recipients studied here. Second, the two selection criteria used by Bonoli and Liechti, immigrant status and low education differ from the one we focused on, which is poor mental health. Third, the analysis presented covered another period than the above-mentioned Norwegian studies. The described policy changes that took place during the 2000s have strongly affected the conditions in which the active labor market policy has been implemented.

\section{Strengths and limitations}

The linked design of the study provided comprehensive information about the health status of the recipients, their work history, as well as information that often is regarded as unobservable, like their general perception of themselves. In addition, the information from the administrative registers made it possible to study both the follow-up that was given by the support services over long period of time, their connection to the labor market and the reception of public benefits. Still, there are factors that might have an impact on the overall validity of the results.

The small sample size might affect to what degree the results can be regarded as representative for the whole population. Variables that were found to be statistically nonsignificant in this analysis might be true in the population. The survey sample was representative of the population in the 14 municipalities (Dahl \& van der Wel 2009), but comparisons to national statistics indicated that our sample had lower educational level and fewer immigrants, while being similar with regard to age, sex and marital status (van der Wel et al. 2006). The observed biases thus do not suggest that our sample is systematically less disadvantaged than the population. Nevertheless, while our data are likely to be indicative of the national long-term social assistance population, we cannot rule out the possibility that our sample is somewhat skewed. 
It can also be questioned to what extent psychological distress measured with Hopkins Symptoms Check List is valid over a period of six years. Since the information about health stems from the 2005 questionnaire, the data do not allow us to include the possible impact of mental health treatment or that some mental health conditions might improve. In this analysis, we have limited the study period to 2004-2009. We do however have access to additional register data that makes it possible to follow the cohort until 2013. In the years 2012 and 2013, the variable psychological distress still had explanatory power, which indicates that the measure stands up over time.

The analysis does not consider that the labor market situation might have changed during the period. In order to affect the results, these changes must have had a different impact on the group that reported psychological stress compared to those without mental health problems. The cohort is characterized by being distant from the labor market, having health problems, and low scores on social capital, leading us to assume that any changes in the supply and demand for labor will have the same effect on both ALMP and labor market participation.

Also, over a period of six years, both the individual characteristics and the economic situation of the individuals might change. As Figure 2 showed, those who reported psychological distress did not get paid employment to the same extent as the rest of the sample. Instead, a larger proportion qualified for permanent disability pension over time. This means that the composition of those in demand for vocational training developed differently over time, removing those individuals with highest employability among those without mental health problems, and lowest employability among those who reported psychological distress. Thus, if this selection mechanism is valid, we might have underestimated the mental health access bias during the different policy periods.

Finally, focusing on the period from 2004 till 2009 made it possible to include two large reforms targeted at recipients of social assistance benefits. A reasonable question is whether the observed patterns are still likely to have relevance 10 years later. The composition of the recipients may have changed, and the ambitions of the welfare system in providing work also for the mentally ill have clearly increased (OECD 2013). In recent years, however, we have seen rising proportions of people with mental disorders among those permanently excluded from work (Nav 2020). Further, compared to groups with physical disabilities, the employment rate among the mentally ill is still only about half (Statistics Norway 2017). Although these developments may have several reasons, they are clearly indicative of a continued relevance of our results.

\section{Conclusion}

Despite the small sample available to us, the differences in program participation observed in this study were quite clear. The recipients of social assistance benefits that reported psychological distress had a lower participation rate than those who did not. The finding raises important questions about differential access to labor market programs - or differential needs - among nonemployed with and without mental health problems. Research into the interplay between the management of social services, such as management-by-objectives, and individual caseworkers' practices and priorities, may shed more light on the gap in the participation rate. Hence, our study confirms the need

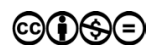


for future research that focus on recruitment processes into ALMPs. Furthermore, new social policy initiatives should aim at removing possible barriers that prevent individuals with mental health problems getting the qualifications and skills they need to acquire a job successfully, particularly when ALMP participation is a scarce resource.

\section{References}

Askim, J., Fimrete, A. L., Moseley, A. \& Pedersen, L. H. (2011). One-Stop Shops for Social Welfare: The Adaptation of an Organizational Form in Three Countries, Public Administration. Volume 89, Issue 4. Blackwell Publishing Ltd. doi: https://doi.org/10.1111/ j.1467-9299.2011.01933.x.

Bassi, L. J. (1984). Estimating the effect of training programs with non-random selection, The Review of Economics and Statistics 66(1): 36-43.

Bonoli, G. \& Liechti, F. (2018). Good intentions and Matthew effects: access biases in participation in active labour market policies, Journal of European Public Policy 25(6): 894-911. doi: https://doi.org/10.1080/13501763.2017.1401105.

Bryant. T., Raphael, D., \& Rioux, M. (2010). Staying Alive: Critical Perspectives on Health, Illness and Health Care, 2nd edition, Toronto: Canadian Scholars' Press.

Cast, A. D. \& Bruke, P. J. (2002). A theory of self-esteem, Social Forces 80(3): 1041-1068. doi: https://doi.org/10.1353/sof.2002.0003.

Caswell, D. \& Larsen, F. (2017). Frontline Work in the delivery of Danish Activation Policies: and How Governance, Organizational and Occupational Contexts Shape This. In Van Berkel, R., Caswell, D., Kupka, P. \& Larsen, F (Eds.), Frontline Delivery of Welfare-to-Work Policies in Europe: Activating the Unemployed, Routledge. doi: https://doi. org/10.4324/9781315694474-10.

Dahl, E. (2003). Does 'workfare' work? The Norwegian experience, International Journal of Social Welfare 12: 274-288. doi: https://doi.org/10.1111/1467-9671.00282.

Dahl, E. \& Lorentzen, T. (2007). Arbeidsrettede tiltak for sosialhjelpsmottakere. Seleksjon, effekter og politiske implikasjoner [Active labour market programs for receipients of social assistance benefits. Selection, effects and political implications], Søkelys på arbeidslivet 2(24): 149-158.

Dahl, E. \& van der Wel, K. (2009). Å forske på marginaliserte grupper; noen metodiske og forskningsetiske utfordringer [Doing Research on Marginalized Groups; Methodological and Ethical Challenges], Fontene forskning: et tidsskrift fra Felles-organisasjonen (FO). 2009(1): 54-64.

Duell, N., Singh, S. \& Tergeist, P. (2009). Activation Policies in Norway, OECD Social, Employment and Migration Working Papers, No. 78, OECD Publishing, Paris. doi: https:// doi.org/10.1787/226388712174.

Drucker, P. F. (1954). The Practice of Management, Harper \& Row, New York, NY.

Eurostat (2013). Labour market policy statistics - Methodology 2013. Eurostat Manuals and Guidelines. Luxembourg: Publications Office of the European Union, 2013.

Halvorsen, K. (1999). Employment commitment among long-term unemployed in Norway. Is a culture of dependency about to develop? European Journal of Social Work 2(2): 177-192. doi: https://doi.org/10.1080/13691459908413816.

Hardoy, I. (2005). Impact of multiple labour market programmes on multiple outcomes: the case of Norwegian youth programmes, Labour 19: 425-467. doi: https://doi.org/10.1111/ j.1467-9914.2005.00312.x.

Heckman, J. J., Heinrich, C. \& Smith, J. (2002). The performance of performance standards, The Journal of Human Resources 17(4): 778-81. 
Heckman, J. J. \& Smith, J. A. (2004). The determinants of participation in a social program: evidence from a prototypical job training program, Journal of Labor Economics 22(2): 243-298. doi: https://doi.org/10.1086/381250.

Hellevik, O. (2009). Linear versus logistic regression when the dependent variable is a dichotomy, Quality \& Quantity 43(1): 59-74. doi: https://doi.org/10.1007/s11135-0079077-3.

Hyggen, C. (2008). Change and stability in work commitment in Norway: from adolescence to adulthood, Journal of Social Policy 37(1): 103-123. doi: https://doi.org/10.1017/ S0047279407001511.

Card, D., Kluve, J., \& Weber, A. (2015). What Works? A Meta Analysis of Recent Active Labor Market Program Evaluations. IZA Discussion Paper Series No. 9236. doi: https:// doi.org/10.3386/w21431.

Langeng, P. I. \& Dehli, T. K. (2011) Kvalifiseringsprogrammet 2007-2010 [The Qualification Program 2007-2010], Nav: Arbeid og Velferd, 2012/1.

Lipsky, M. (1980). Street level bureaucracy: Dilemmas of the individual in public service (30th Anniversary expanded edn in 2010), New York: Russell Sage Foundation.

Lægreid, P. \& Rykkja, L. H. (2013). Coordinating Norwegian welfare: The NAV reform, COCOPS 2013.

Lødemel, I. \& Johannessen, A. (2005). Tiltaksforsøket: Mot en inkluderende arbeidslinje? [The Activation trial: Towards a more inclusive work-line?] HIO-rapport 2005 nr. 1.

Markussen, S. \& K. Røed (2016). Leaving Poverty Behind? The Effects of Generous Income Support Paired with Activation. American Economic Journal: Economic Policy 8: 180-211. doi: https://doi.org/10.1257/pol.20140334.

Modini, M., Joyce, S., Mykletun, A., Christensen, H., Bryant, R. A., Mitchell, P. B., et al. (2016). The mental health benefits of employment: Results of a systematic meta-review, Australasian Psychiatry: Bulletin of Royal Australian and New Zealand College of Psychiatrists 2016. PubMed Central PMCID: PMC26773063. doi: https://doi.org/ $10.1177 / 1039856215618523$.

Murray, C. (1984). Losing Ground, New York: Basic Books.

Nav (2019). Statistics over recipients of disability benefits by diagnosis. nav.no.

Nielsen, V. L. (2006). Are street-level bureaucrats compelled or enticed to cope? Public Administration 84(4): 861-889. doi: https://doi.org/10.1111/j.1467-9299.2006.00616.x.

Nordenmark, M. (1999). Employment commitment and psychological well-being among unemployed men and women, Acta Sociologica 42: 135-146. doi: https://doi.org/10.1177/ 000169939904200203.

Norwegian Ministry of Labour and Social Inclusion and Norwegian Ministry of Health and Care Services (2007). National Strategic Plan for Work and Mental Health 2007-2012, Government Administration Services 01/2009.

OECD (2010). Sickness, Disability and Work: Breaking the Barriers. A Synthesis of Findings across OECD Countries, Paris: OECD Publishing. doi: https://doi.org/10.1787/9789264088856-en.

OECD (2012). Sick on the Job? - Myths and Realities about Mental Health and Work, Paris: OECD Publishing. doi: https://doi.org/10.1787/22257985.

OECD (2013). Mental Health and Work - Norway, Paris: OECD Publishing. doi: https://doi. org/10.1787/9789264178984-en.

OECD (2015). Fit Mind, Fit Job: From Evidence to Practice in Mental Health and Work, Mental Health and Work, Paris: OECD Publishing. doi: https://doi.org/0.1787/9789264228283-en.

Parsons, T. (1991). The Social System, Routledge.

Pearlin, L. I. \& Schooler, C. (1978). The structure of coping, Journal of Health and Social Behavior 2-21. doi: https://doi.org/10.2307/2136319. 
Roaldsnes, A. (2018). Navs hovedmål sett fra NAV-kontoret - En kvantitativ analyse av overgang til arbeid [NAV's main goal seen from the Nav office - A quantitative analysis of the transition to work], Nav: Rapport 2 // 2018.

Rodriguez-Planas, N. (2010). Channels through which public employment services and small-business assistance programs work, Oxford Bull Econ Stat 72(4): 458-485. doi: https://doi.org/10.1111/j.1468-0084.2010.00593.x.

Rønsen, M. \& Skarðhamar, T. (2007). Do welfare-to-work initiatives work? Evidence from an activation programme targeted at social security recipients in Norway, Discussion Papers 519, Statistics Norway, Research Department.

Røysum, A. (2010). Nav-reformen: Sosialarbeidernes profesjon utfordres. [The NAV reform: The profession of social work has been challenged], Fontene forskning Nr. 1-2010.

Røysum, A. (2014). Ubehaget ved å forenkle det komplekse [The Discontent in Simplifying the Complexity]. In Ubehaget i sosialt arbeid [Social Work and Its Discontent], edited by Anbjørg Ohnstad, Marianne Rugkåsa, and Signe Ylvisaker, 141-159, Oslo: Gyldendal Akademisk.

Schafft, A. \& Spjelkavik, Ø. (2011). Evaluering av Kvalifiseringsprogrammet: sluttrapport. [An Evaluation of the Qualification Program: Final Report]. AFI-rapport 4/2011, Oslo: Arbeidsforskningsinstituttet.

Statistics Norway (2017). The Norwegian Labour Force Study ad hoc module on disabled people, Oslo.

Strand, B. J., Dalgard, O. S., Tambs, K. \& Rognerud, M. (2003). Measuring the mental health status of the Norwegian population: A comparison of the instruments SCL-25, SCL-10, SCL-5 and MHI-5 (SF-36), Nordic Journal of Psychiatry 57(2): 113-118. doi: https://doi. org/10.1080/08039480310000932.

Sutton, L., Cebulla, A., Heaver, C. \& Smith, N. (2004). Drug and alcohol use as barriers to employment: a review of the literature, CRSP research report; 499s, Loughborough: University for Department for Work and Pensions.

UN CRPD (2006). Convention on the Rights of Persons with Disabilities. Resolution adopted by the General Assembly, 24 January 2007; A/RES/61/1 06, Available at: https://www. un.org/development/desa/disabilities/convention-on-the-rights-of-persons-with-disabilities.html [Accessed October 1, 2019].

van der Wel, K., Dahl, E., Lødemel, I., Løyland, B., Naper, S. O., and Slagsvold, M. (2006). Funksjonsevne bland langtidsmottakere av sosialhjelp (Functional ability of long-term recipients of social assistance benefits), HIO-rapport $2006 \mathrm{nr} .29$.

Van Kersbergen, K., Hemerijck, A. (2012). Two decades of change in Europe: the emergence of the social investment state, Journal of Social Policy 41: 475-492. doi: https://doi. org/10.1017/S0047279412000050.

Warr, P., Cook, J., \& Wall, T. (1979). Scales for the measurement of some work attitudes and aspects of psychological well-being, Journal of occupational Psychology 52(2): 129-148. doi: https://doi.org/10.1111/j.2044-8325.1979.tb00448.x.

Williams, C. \& Johnson, M. R. D. (2010). Race and Ethnicity in a Welfare Society, Maidenhead: Open University Press.

Winter, S. \& Nielsen, V. L. (2008). Implementering af politik [Implementation of public policy], Århus: Academica.

Zhang, T. (2003). Identifying treatment effects of active labour market programmes for Norwegian adults. Memorandum 26/2003, Oslo University, Department of Economics. 